\title{
O VALOR DOS VALORES: A PERSPECTIVA DE PAIS EM RELAÇÃO A SEUS FILHOS
}

\author{
Felipe Queiroz Siqueira \\ Universidade Federal do Rio Grande do Sul \\ Tiago Zanatta Calza \\ Universidade Federal do Rio Grande do Sul \\ Jorge Castellá Sarriera \\ Universidade Federal do Rio Grande do Sul
}

Lia Beatriz de Lucca Freitas

Universidade Federal do Rio Grande do Sul

\begin{abstract}
Resumo
Este estudo baseou-se na teoria ecológico-cultural. O objetivo foi identificar, em pais de crianças e adolescentes, quais valores eles consideram mais e menos importantes para seus filhos. Vinte e dois participantes responderam a uma escala que avalia a importância de 27 valores. Após, participaram de uma entrevista semiestruturada, elencando os três valores mais importantes e os três menos, bem como justificando suas escolhas. Foram considerados mais importantes: honestidade, justiça e determinação. Os menos importantes foram: ambição, seguir regras dos pais e liderança. Dentre as justificativas dos mais importantes, destacaram-se: respeitar a alteridade, ser um meio para atingir objetivos e englobar outros valores. Nos menos importantes, destacaram-se: acarretar prejuízos, não ser essencial e não ser garantia de sucesso. Discutem-se os resultados à luz da literatura. Ressaltam-se a importância dos valores enquanto assunto interdisciplinar e a necessidade de reflexão sobre quais tipos de valores se deseja desenvolver na sociedade.
\end{abstract}

Palavras-chave: valores; pais; criação dos filhos; moralidade.

\section{THE VALUE OF VALUES: THE PERSPECTIVE OF PARENTS TOWARDS THEIR CHILDREN}

\begin{abstract}
This study was based on cultural-ecological theory. The aim was to identify, in parents of children and adolescents, what values they consider more and less important, and to analyze their justifications. Twenty-two parents answered a scale to assess the importance of 27 values and a semi-structured interview, in which they listed the three most and three least important values, justifying their choices. The most important values were: honesty, justice and determination. The three least important were: ambition, following parents' rules and leadership. Justifications for the most important values included: respecting others, permitting the achievement of one's goals, and including other values. The least important included: causing damage, being unessential, and not guaranteeing success. Results were discussed based on the literature. We emphasized the importance of values as an interdisciplinary subject and the necessity to reflect upon the values we want to develop in our society.

Keywords: values, parents, parenting, morality.
\end{abstract}




\title{
EL VALOR DE LOS VALORES: LA PERSPECTIVA DE LOS PADRES EN RELACIÓN A SUS HIJOS
}

\begin{abstract}
Resumen
Este estudio fue basado en la teoría ecológica-cultural. El objetivo fue identificar, en padres de niños y adolescentes, que valores consideran más y menos importantes para sus hijos, y sus justificaciones. Veintidós padres respondieron un cuestionario que evalúa la importancia de 27 valores, y una entrevista semiestructurada, indicando los tres valores más y menos importantes, y justificando sus indicaciones. Fueron considerados más importantes: honestidad, justicia y determinación. Los menos importantes fueron: ambición, seguir las reglas de los padres y liderazgo. Entre las justificaciones para los más importantes, se destacaron: respeto al otro, ser un medio para alcanzar objetivos e incluir otros valores. Para los menos importantes, se destacaron: causar daños, no ser esencial y no garantizar éxito. Se discuten los resultados a través de la literatura. Se destacan la importancia de los valores como materia interdisciplinaria y la necesidad de reflexionar sobre que valores se deseaSe Destacan desarrollar en la sociedad.
\end{abstract}

Palabras clave: valores; padres; criar a los hijos; moralidad.

\section{INTRODUÇÃO}

Muitas pessoas consideram que atualmente há uma falta ou inversão dos valores, o que estaria prejudicando as relações humanas (La Taille \& Menin, 2009). Para alguns, os pais não se importam mais com a educação de seus filhos, deixando-os sem referências ou propiciando apenas exemplos materialistas. Mas será, realmente, que os pais não julgam importante transmitir valores para seus filhos? Será que os valores admirados pelos pais têm se modificado?

Conferir valor a um objeto ou qualidade consiste em atribuir-lhe importância. Quando se diz que uma comida está saborosa ou que a justiça é relevante, na verdade, se está valorizando tais conteúdos. Também há atribuição de valor quando se afirma que certas características não são importantes ou que não se gosta de determinado objeto. Nesses casos, porém, a valorização atua no sentido de considerar tais conteúdos de forma indesejável ou, no mínimo, menos desejável. Conceitualmente, o valor consiste na expressão da desejabilidade em todos os níveis, existindo desde as primeiras trocas entre o sujeito e o mundo exterior (Piaget, 1936/2014a, 1954/2014b). Assim, toda conduta humana tem como objetivo um fim determinado, que tem valor porque desejado (Prestes, Castro, Tudge, \& Freitas, 2014). Aquilo que uma pessoa deseja ou considera importante refere-se, portanto, ao que ela valoriza. Por isso, investigar os desejos e os julgamentos sobre o que é relevante para alguém é também uma maneira de acessar seus valores.

Apesar de Piaget (1932/1994, 1936/2014a, 1954/2014b) ter elaborado apenas o esboço de uma teoria dos valores, seus escritos auxiliam a entendê-los. Para ele, no decorrer da vida os indivíduos assimilam valores da cultura e aprendem a hierarquizá-los (Prestes et al., 2014). Constrói-se, então, uma escala de valores, a qual é para o sujeito sua razão de ser (Piaget, 1954/2014b). Aquilo que uma pessoa mais valoriza ocupa o topo de sua escala: é este valor 
que dá sentido - direção e significado - a sua vida. Os demais valores, localizados em outros pontos da escala, são meios para chegar a esse fim (Prestes et al., 2014). Por exemplo, se um indivíduo considera como valor mais importante ser poderoso, o sentido de sua vida será a busca pelo poder. Ele pode até desejar ser cooperativo ou estudioso também, mas esses valores serão significativos apenas na medida em que possibilitam atingir posições de prestígio, como cargos de chefia ou presidência.

Schwartz (2012) traçou elementos universais em relação à questão dos valores. Para o autor, seriam crenças que guiam ações, que transcendem situações específicas, e que seriam ordenados por importância, sendo esta elencada na avaliação de um valor em relação a outro. Neste caso, o sistema de valores é compreendido como o orientador das motivações básicas do ser humano, traduzindo o que é mais ou menos importante na vida deste. Todavia, estudos sob essa perspectiva não têm se voltado à questão dos valores relacionados à criação dos filhos.

Nas últimas décadas, as pesquisas em psicologia têm demonstrado crescente interesse acerca dos valores de pais e filhos, devido a sua relevância no que se refere ao desenvolvimento individual e ao funcionamento da sociedade (Barni, Alfieri, Marta, \& Rosnati, 2013). Desse modo, entende-se que os pais não somente desejam transmitir a seus filhos aquilo que eles próprios valorizam, mas também o que percebem enquanto algo importante para a sociedade (Tam, Lee, $\mathrm{Kim}, \mathrm{Li}, \&$ Chao, 2012). Cabe atentar também que os estudos que trabalham com o tema da parentalidade consideram esta função como não necessariamente desempenhada por pais biológicos, podendo também ser exercida por outros cuidadores, como avós, madrastas, padrastos, irmãos, etc. (Dellazzana \& Freitas, 2012; Pinto, Arrais, \& Brasil, 2014; Sousa, Amaral, \& Dias, 2014).

Martins et al. (2015) argumentam que os valores na criação dos filhos são influenciados pelo pertencimento dos pais em um ou outro grupo cultural. Esta ideia baseia-se no modelo proposto por Kağitçibaşi (2012), o qual postula que as características dos grupos devem ser consideradas através de duas dimensões ortogonais: (a) uma referente à agência (autonomia ou heteronomia) e (b) outra referente à distância interpessoal (relação ou separação). A primeira diz respeito à extensão com que os pais encorajam a independência ou a obediência $e$, a segunda, ao quanto eles valorizam que os filhos sejam mais separados ou relacionados aos outros. Em relação à primeira dimensão, Formiga e Souza (2012) apontam que uma orientação mais autônoma ou heterônoma irá resultar em diferentes maneiras de se comportar, tanto no que se refere à autopercepção quanto aos relacionamentos interpessoais. Keller (2012), todavia, indicou que há dois diferentes tipos de autonomia: (a) autonomia psicológica, típica da classe média e voltada a encorajar as crianças a pensar e fazer planos por si mesmas; e (b) autonomia da ação, própria de famílias com pouca educação e direcionada 
a oportunizar atividades que permitam seus filhos, por exemplo, realizar tarefas simples.

Kohn (1995) argumentou que os valores de pais na criação dos filhos estão ligados a experiências anteriores de educação e trabalho. Como, no geral, os pais querem o sucesso dos filhos, as diferenças de valores entre eles residem naquilo que acham que levará ao sucesso. Enquanto alguns - normalmente com baixo nível de escolaridade e experiência em trabalhos que exigem seguir regras - valorizam a obediência, outros - geralmente com maior nível de educação e experiência em trabalhos que permitem pensar por si próprios - veem o sucesso como resultado da autonomia e autodireção (Tudge et al., no prelo). Outros estudos, realizados em diferentes países (e.g, Estados Unidos, Itália, Japão, Polônia, Ucrânia, Estados Unidos e Rússia), dão suporte a essas ideias (Kohn, Slomczynski, \& Schoenbach, 1986; Kohn et al., 2001; Tudge, Hogan, Snezhkova, Kulakova, \& Etz, 2000).

Tudge et al. (2013) examinaram diferenças de valores na criação de filhos entre pais de diferentes classes sociais. Investigaram, ainda, se estes valores seriam influenciados pelo desenvolvimento das crianças. Participaram 25 pais brasileiros, das classes média (representada por profissionais liberais com frequência de, no mínimo, alguns anos em uma instituição de Ensino Superior) e baixa (constituída por trabalhadores assalariados ou autônomos com pouca escolaridade). Aplicaram-se os instrumentos - entrevistas, observação e questionário - quando as crianças possuíam 3, 36 e 72 meses de idade. Os resultados indicaram que os valores dos pais diferiram por classe social: na classe média, valorizou-se mais autonomia e autodireção, enquanto que, na classe baixa, a conformidade foi mais valorizada. Por sua vez, a força e a direção dos valores na criação dos filhos modificaram-se na medida em que as crianças se desenvolveram. Assim, foi menos provável que os pais valorizassem a autonomia e a autodireção quando seus filhos tinham 36 meses do que quando possuíam 3 ou 72 meses. Além disso, pais de classe média tiveram maior probabilidade de valorizar a conformidade quando suas crianças tinham 36 meses do que quando elas eram mais novas ou mais velhas.

Vieira et al. (2010) estudaram crenças maternas sobre seus próprios valores em uma amostra de 350 mães brasileiras de crianças com menos de 3 anos de idade. Os autores encontraram conexão entre classe social e valores sobre a criação de seus filhos. Enquanto o nível educacional materno foi preditor da importância atribuída a práticas que estimulassem o desenvolvimento dos filhos, o paterno foi preditor da importância que as mães atribuíam a práticas parentais orientadas por regras diárias socialmente aceitas. Já Sarriera et al. (2012) examinaram a influência dos valores que os pais almejam para seus filhos e a possibilidade de sua transmissão, em uma investigação junto a 543 adolescentes e seus cuidadores. Nesse trabalho, os pais atribuíram maior importância a aspectos humanitários e voltados às relações interpessoais (e.g., 
amabilidade e solidariedade), valores relativos à personalidade (e.g., simpatia e otimismo) e habilidades e conhecimentos (e.g., competência profissional e força de vontade). Conferiu-se também menor importância aos valores materiais (e.g., poder e dinheiro). Macedo, Kublikowski, e Berthoud (2006) investigaram quais valores seriam os mais importantes a serem transmitidos aos filhos, junto a onze mães e quatro pais de adolescentes. Apontaram-se como os mais relevantes a honestidade, o respeito, a responsabilidade e valores religiosos. Estratégias para transmitir tais valores consistiram em "conversar, falar, dialogar, agir, demonstrar, ensinar, ouvir, ser honesto e dar bons exemplos, chamar a atenção, dar bronca, castigar" (p. 44).

Apesar de existirem estudos brasileiros sobre valores na criação dos filhos, a grande maioria deles encontra-se nos Estados Unidos (Martins et al., 2015). Além disso, há um predomínio de pesquisas quantitativas (e.g., Kohn et al., 2001; Vieira et al., 2010), com pais de bebês (e.g., Martins et al., 2015; Tudge et al., 2013) ou adolescentes (e.g., Macedo et al., 2006; Sarriera et al., 2012). Observa-se, então, uma necessidade de se realizarem estudos qualitativos relativos a pais com filhos não apenas bebês ou adolescentes, uma vez que a idade dos filhos interfere nos valores parentais (Tudge et al., 2013). Por conta disso e considerando-se que alguns estudiosos se referem a uma possível transformação dos valores na sociedade (La Taille \& Menin, 2009), o objetivo deste estudo é identificar, em pais de jovens de 9 a 16 anos, quais valores eles consideram mais e menos importantes para seus filhos, bem como analisar qualitativamente suas justificativas. Esta pesquisa baseou-se na teoria ecológicocultural (Tudge, 2008; Tudge et al., no prelo), a qual considera que as atividades e interações dos indivíduos são influenciadas pelo grupo cultural do qual fazem parte, pelo tempo histórico em que ocorrem e pelas características pessoais dos sujeitos. Utilizaram-se ainda autores de outras perspectivas teóricas (e.g., Piaget, 1932/1994, 1954/2014b; Schwartz, 2012) com o intuito de enriquecer a exposição sobre o tema dos valores.

\section{MÉTODO}

Este estudo contou com a participação de pais ou cuidadores de crianças e adolescentes. A coleta e a análise dos dados basearam-se em procedimentos tanto de caráter quantitativo quanto qualitativo. Os participantes preencheram uma ficha de dados sociodemográficos, bem como responderam a uma escala e a uma entrevista semiestruturada, como detalhado a seguir.

\section{Participantes}

Participaram deste estudo 22 pais ou cuidadores de crianças e adolescentes com idades entre 9 e 16 anos, os quais afirmaram ser responsáveis pela criação deles. Todos eram moradores de Porto Alegre-RS. Havia 14 mães, 
seis pais, um casal de avós e uma madrasta. A média de idade dos pais ou cuidadores foi de 43,1 anos (DP $=5,1$ ) e a dos filhos foi de 12,1 anos (DP = $3,4)$. Quanto ao nível de escolaridade, 31,9\% dos participantes haviam cursado até o Ensino Médio, enquanto que 54,5\% haviam frequentado, no mínimo, alguns anos em uma instituição de Ensino Superior. Três participantes $(13,6 \%)$ não informaram a escolaridade.

\section{Instrumentos}

\section{Ficha de dados sociodemográficos}

Elaborada para obter dados dos pais relativos ao grau de parentesco com o jovem, à idade e ao nível educacional. Esta ficha teve como objetivo possibilitar uma descrição da amostra.

\section{Parent's Values for their Children's}

Adaptado de Martins et al. (2015) e baseado na ideia de que os valores de pais na criação dos filhos estão relacionados a experiências anteriores (Kağitçibaşi, 2012; Kohn, 1995). É composto por 27 itens, correspondentes a 27 valores: ambicioso, honesto, responsável, respeitoso, defender seu ponto de vista, ter compaixão, cooperativo, determinado, respeitar os mais velhos, empático, justo, generoso, grato, independente, ter iniciativas, gentil, líder, leal, obediente, persistente, polido, respeitoso, seguir as regras dos pais, autoconfiante, sociável, organizado e tolerante. O participante deveria responder o quanto é importante que um filho tivesse aquele valor, em uma escala likert de seis pontos.

\section{Entrevista semiestruturada}

A partir de 27 cartões correspondentes a cada valor presente na Escala Parent's Values for their Children's, os participantes foram convidados a participar de uma entrevista semiestruturada. Por todos os valores serem de certa forma desejáveis, sentiu-se a necessidade de investigar quais seriam os mais importantes dentre todos e os menos relevantes dentre todos (Tudge et al., 2013), uma vez que as médias não seriam suficientes para mensurar adequadamente as minúcias das diferenças entre eles. Solicitou-se, então, que os pais fizessem quatro escolhas desses valores através das seguintes perguntas:

1. Escolha 1 Abrangente, com todos os 27 cartões presentes na mesa ("Quais as três características que você considera mais importantes que um filho seu tenha? Por quê?");

2. Escolha 1 Específica, com somente os 3 cartões selecionados na Escolha 1 Abrangente ("Destas três, qual é a mais importante? Por quê?"); 
3. Escolha 2 Abrangente, novamente com os 27 cartões na mesa ("Quais as três características que você considera menos importantes que um filho seu tenha? Por quê?");

4. Escolha 2 Específica, com somente os 3 cartões elencados na Escolha 2 Abrangente ("Destas três, qual é a menos importante? Por quê?)".

Com base nas diretrizes propostas por Minayo (2010), possibilitou-se que o entrevistado discorresse sobre o tema proposto. O participante ficou livre para expressar seus pensamentos e opiniões.

\section{Procedimentos}

\section{Coleta de dados}

Inicialmente, realizou-se contato com os pais ou cuidadores de crianças e adolescentes já cadastrados em um banco de dados. Em sala reservada, estes foram convidados a responder a escala Parent's Values for their Children's. Realizou-se, em seguida, a entrevista semiestruturada no mesmo local. As entrevistas foram gravadas e, após, transcritas na íntegra, gerando um protocolo para cada participante.

Este estudo seguiu as diretrizes e normas da Resolução 466/2012 do Ministério da Saúde, tendo sido aprovado pelo Comitê de Ética em Pesquisa do Instituto de Psicologia da Universidade Federal do Rio Grande do Sul, protocolo $n^{\circ}$ 22485. Todos os participantes foram informados acerca da pesquisa e seus objetivos e preencheram um Termo de Consentimento Livre e Esclarecido, concordando com a participação. Para garantir o anonimato dos participantes, todos os instrumentos respondidos e protocolos foram identificados apenas com números.

\section{Análise de dados}

Os dados da Escala foram analisados, no SPSS 20, através das análises descritivas, a fim de observar as médias e os desvios-padrão de cada item. Para as entrevistas, realizou-se um levantamento de frequência dos valores citados como mais importantes (Escolha 1 Abrangente e Específica) e menos importantes (Escolha 2 Abrangente e Específica). Após, analisaram-se as justificativas dos três valores mais mencionados nas Escolhas 1 e com as maiores médias na escala, assim como os três mais citados nas Escolhas 2 e com as menores médias. Como critério de inclusão, os valores deveriam ter sido classificados como os três mais ou os três menos importantes em todas as modalidades (Escala, Escolhas Abrangentes e Específicas).

As justificativas foram categorizadas através de uma análise de conteúdo (Bardin, 1977/2010), para a qual foram realizadas as etapas sequenciais de préanálise, exploração do material ou codificação, e tratamento dos resultados (inferência e interpretação). Dois juízes categorizaram os dados de forma 
independente. Quando houve discordâncias, cada juiz apresentou o seu ponto de vista e realizou-se um acordo entre eles.

\section{RESULTADOS}

As análises descritivas da Escala Parent's Values for their Children's indicaram uma maior importância atribuída aos valores honesto, justo, determinado e respeitar os mais velhos. Os valores considerados menos importantes foram: ambicioso, seguir regras dos pais e líder.

A seguir, apresentam-se as médias e desvios-padrão dos 27 itens da escala: honesto $(M=4,95 ; D P=0,21)$; justo $(M=4,91 ; D P=0,29)$; determinado $(M=4,91 ; D P=0,29)$; respeitar os mais velhos $(M=4,91 ; D P=$ $0,29)$; responsável $(M=4,86 ; D P=0,35)$; cooperativo $(M=4,86 ; D P=0,35)$; ter iniciativa $(M=4,82 ; D P=0,39)$; respeitoso $(M=4,77 ; D P=0,52)$; leal $(M$ $=4,77 ; \mathrm{DP}=0,42)$; autoconfiante $(\mathrm{M}=4,77 ; \mathrm{DP}=0,42)$; ter compaixão $(\mathrm{M}=$ $4,77 ; \mathrm{DP}=0,42)$; humilde $(M=4,73 ; \mathrm{DP}=0,45)$; persistente $(M=4,73 ; \mathrm{DP}=$ $0,55)$; gentil $(M=4,68 ; D P=0,56)$; independente $(M=4,68 ; D P=0,47)$; grato $(M=4,68 ; D P=0,56)$; generoso $(M=4,64 ; D P=0,58)$; defender seu ponto de vista $(M=4,59 ; D P=0,50)$; sociável $(M=4,50 ; D P=0,80)$; organizado $(M=$ $4,50 ; D P=0,91)$; tolerante $(M=4,27 ; D P=0,82)$; polido $(M=4,27 ; D P=$ $0,82)$; obediente $(M=4,23 ; D P=0,81)$; empático $(M=4,05 ; D P=1,04)$; líder $(M=3,95 ; D P=0,72)$; seguir regras dos pais $(M=3,73 ; D P=1,03)$; ambicioso $(M=3,09 ; D P=0,92)$.

Os valores mais frequentemente elencados na Escolha 1 Abrangente foram: honesto $(N=13)$, determinado $(N=11)$ e responsável $(N=9)$. $\mathrm{Na}$ Escolha 1 Específica, os mais mencionados foram honesto $(\mathrm{N}=8)$, responsável $(N=5)$, determinado $(N=2)$ e autoconfiante $(N=2)$. Os valores das Escolhas 1 estão presentes na Tabela 1. 
Tabela 1. Frequência dos Valores Mais Importantes: Escolha 1 Abrangente e específica

\begin{tabular}{lcc}
\hline Valores & $\mathrm{N}$ & $\%$ \\
\hline Escolha 1 Abrangente & & \\
Ser honesto & 13 & 19,7 \\
Ser determinado & 11 & 16,7 \\
Ser responsável & 9 & 13,6 \\
Ser humilde & 6 & 9,1 \\
Ser justo & 4 & 6,2 \\
Ser persistente & 4 & 6,2 \\
Ter iniciativa & 3 & 4,5 \\
Ser autoconfiante & 3 & 4,5 \\
Ser organizado & 2 & 3,0 \\
Ter compaixão & 2 & 3,0 \\
Respeitar ponto de vista & 2 & 3,0 \\
Ser cooperativo & 1 & 1,5 \\
Respeitar os mais velhos & 1 & 1,5 \\
Ser grato & 1 & 1,5 \\
Ser independente & 1 & 1,5 \\
Ser respeitoso & 1 & 1,5 \\
Seguir as regras dos pais & 1 & 1,5 \\
Ser tolerante & 1 & 1,5 \\
Total & 66 & 100 \\
Escolha 1 Específica & & \\
Ser honesto & 8 & 36,4 \\
Ser responsável & 5 & 22,7 \\
Ser determinado & 2 & 9,2 \\
Ser autoconfiante & 1 & 9,2 \\
Respeitar os mais velhos & 1 & 4,5 \\
Respeitar pontos de vista & 1 & 4,5 \\
Ser humilde & 22 & 100 \\
Ser persistente & 1,5 \\
Seguir regras dos pais & 1 & \\
Total & & \\
\hline & & \\
\hline
\end{tabular}

Os valores mais citados na Escolha 2 Abrangente foram: seguir as regras dos pais $(\mathrm{N}=15)$, ambicioso $(\mathrm{N}=14)$ e líder $(\mathrm{N}=10)$. Para a Escolha 2 Específica, elencaram-se com maior frequência: ambicioso ( $N=8)$, seguir as regras dos pais $(N=8)$, líder $(N=2)$ e polido $(N=2)$. Os valores das Escolhas 2 estão na Tabela 2. 
Tabela 2. Frequência dos Valores Menos Importantes: Escolha 2 Abrangente e específica

\begin{tabular}{lcc}
\hline Valores & $\mathrm{N}$ & $\%$ \\
\hline Escolha 2 Abrangente & & \\
Seguir as regras dos pais & 15 & 22,7 \\
Ser ambicioso & 14 & 21,2 \\
Ser líder & 10 & 15,2 \\
Ser polido & 5 & 7,7 \\
Ser tolerante & 4 & 6,2 \\
Ser empático & 3 & 4,5 \\
Ser obediente & 3 & 4,5 \\
Ser autoconfiante & 3 & 4,5 \\
Ser independente & 2 & 3,0 \\
Respeitar ponto de vista & 1 & 1,5 \\
Ser grato & 1 & 1,5 \\
Ser humilde & 1 & 1,5 \\
Tomar iniciativas & 1 & 1,5 \\
Ser persistente & 1 & 1,5 \\
Ser sociável & 1 & 1,5 \\
Ser organizado & 1 & 1,5 \\
Total & 66 & 100 \\
Escolha 2 Específica & & \\
Ser ambicioso & 8 & 36,4 \\
Seguir as regras dos pais & 8 & 36,4 \\
Ser lider & 2 & 9,1 \\
Ser polido & 2 & 9,1 \\
Ser empático & 1 & 4,5 \\
Ser tolerante & 1 & 4,5 \\
Total & 22 & 100 \\
\hline
\end{tabular}

Os três valores que mais se repetiram em todas as modalidades de questionamento (Escala, Escolhas Abrangentes e Escolhas Específicas) em relação aos valores mais importantes foram: honesto, determinado e responsável. No que se referem aos valores menos importantes, os mais mencionados foram: ambicioso, seguir as regras dos pais e líder. A seguir, apresentam-se as justificativas dos pais em relação aos valores mais citados. Optou-se por analisar qualitativamente apenas os três valores mais frequentes em função de uma maior disponibilidade de justificativas. Apresentam-se os participantes por meio do número de identificação de cada um.

Honesto

Meio para atingir um objetivo

Considera-se a honestidade como uma característica necessária para se alcançar certos objetivos. Em alguns casos, a meta é inespecífica: "a pessoa que 
é honesta se destaca em tudo, ela consegue o que ela quer" (P91). Em outros, é mais explícita: "nunca um honesto vai prejudicar alguém" (P106).

\section{Finalidade}

Ser honesto não é apenas um meio para se alcançar um objetivo, mas um fim em si mesmo. É um valor necessário para se agir da maneira correta. Por exemplo: "[a honestidade] é um porto seguro, onde tu sempre vai te sentir à vontade, porque tu sempre fez, na tua ótica pelo menos, aquilo que tu achou certo" (P240). A honestidade também é algo que engloba outros valores relevantes. Segue uma ilustração: "ser honesto engloba várias coisas que a gente deve ser: ser sociável, respeitar os mais velhos" (P135).

\section{Determinado}

\section{Perseguir os objetivos}

A determinação possibilita perseguir seus objetivos. Sem ela, não se pode conseguir o que se almeja e o indivíduo fica em uma situação ruim. Por exemplo: "ele tem que ter essa determinação para ter início, meio e fim, para chegar a cumprir os objetivos dele" (P138); "se a pessoa não se determina a fazer tal coisa, não consegue fazer nada" (P126).

\section{Ser uma pessoa melhor}

Permite melhorar a si mesmo em vários sentidos e, consequentemente, tornar-se um indivíduo melhor. Segue um exemplo: "acho que ele vai ser uma pessoa melhor, um profissional melhor, um pai melhor, um marido melhor, um ser humano melhor" (P395).

\section{Responsável}

\section{Cumprir compromissos}

A responsabilidade relaciona-se ao cumprimento dos compromissos assumidos, no presente ou no futuro, não sendo um valor relevante por si mesmo. Por exemplo: "se eu assumo um compromisso, tenho que ser responsável com aquilo" (P108); "tu vai ser responsável, tu vai cumprir teu horário, tu vai cumprir as normas, né?" (P106).

\section{É um fim em si}

Consiste em assumir seus atos, fazer o que é certo e justo. O valor é considerado relevante em si mesmo. Por exemplo: "nós temos que assumir sempre. [...] Aquela história de não pôr a culpa em outra pessoa, assumir seus atos" (P240). Além disso, relaciona-se com outros valores importantes, principalmente, com a honestidade. Verbalizaram-se o seguinte: "a responsabilidade está atrelada com a honestidade" (P240); "acho que tudo que 
tu faz com responsabilidade tu já está colocando tudo isso aqui junto [os outros valores da escala]" (P390).

\section{Ambicioso}

\section{Acarreta prejuízos}

Considera-se prejudicial por causar malefícios para si próprio e para as outras pessoas. Por exemplo: "acabam trazendo mal para elas ou para quem tá na volta delas" (P127). Para alguns, é danoso apenas quando em demasia, ou seja, é importante quando moderado e prejudicial se em excesso. Verbalizou-se o seguinte: "ser ambicioso demais pode te levar a um desvio, né, do teu caminho" (P122).

Não é garantia de satisfação

É um falso ideal de felicidade, podendo causar frustrações. A pessoa ambiciosa não conseguiria estar satisfeita, uma vez que ela estaria constantemente desejando alcançar aquilo que ainda não possui. Citaram-se as frases: "dinheiro não traz toda a felicidade que tu quer" (P146); "ela sempre vive uma eterna frustração, porque ela sempre vai pro degrau seguinte, e muitas vezes é difícil" (P240).

\section{Não é essencial}

Considera-se um valor menor em relação a outros, não sendo fundamental na vida das pessoas. Consiste em um valor menos relevante por ser comparado a outros que possuem maior importância. Seguem-se exemplos: "tem outras coisas mais importantes, sabe?" (P91); "eu queria que ela tivesse mais valores humanos que valores materiais" (P327).

\section{Seguir as regras dos pais}

\section{Criar as próprias regras}

É mais importante que os filhos tenham liberdade de fazer suas próprias escolhas do que seguir as regras dos pais, especialmente quando eles se tornarem adultos. Verbalizaram-se as seguintes frases: "eles têm que tomar conta da vida deles e não fazer o que eu acho" (P91); "ela tem que saber o que é melhor para ela, né, ela tem que ter o livre-arbítrio dela" (P106); "porque agora ela é obrigada a seguir minhas regras; mas, daqui a pouco, não vai mais seguir" (P126).

\section{Seguir todas as regras pode ser ruim}

Considera-se que nem todas as regras deveriam ser seguidas, uma vez que as seguir indiscriminadamente poderia trazer prejuízos. Seguem algumas frases que exemplificam este tipo de justificativa: "uma pessoa que segue todas as regras todo o tempo se transforma numa pessoa chata e sem iniciativas" 
(P131); "se tu seguir uma coisa, assim, de regra certinho demais, pode não ser tão bom para outra pessoa" (P122).

Líder

É uma consequência natural

É entendido como uma consequência de outras práticas. A liderança poderia vir naturalmente através do exercício de outros valores e atitudes. Seguem algumas verbalizações: "ela tendo outras qualidades aqui, automaticamente os outros vão ver ela até como uma líder" (P106); "sem querer, acaba sendo líder" (P75).

Não é essencial

É considerado um valor menor, não tão necessário para a vida dos filhos, não tendo relação com a felicidade, a dignidade ou uma vida boa. Mencionaramse as seguintes falas: "qual a importância de ser líder?" (P63); "não precisa ser um líder, acho que não é tão importante" (P124).

\section{Pode te prejudicar}

Considerado potencialmente danoso dependendo de como é praticado. A forma pela qual a liderança é exercida pode ser prejudicial. A título de exemplo: "nem sempre é bom ser líder [...] ser confiante demais também faz mal; tu pode pecar por excesso" (P135).

\section{DISCUSSÃO}

Em meio a uma possível transformação dos valores (La Taille \& Menin, 2009), os pais muitas vezes têm sido apontados como culpados por não transmitirem aqueles considerados mais importantes. Sabe-se que a transmissão de valores para a geração seguinte é relevante para o desenvolvimento individual das crianças e o funcionamento da sociedade (Barni et al., 2013). Por isso, este estudo teve o objetivo de identificar, em pais de jovens de 9 a 16 anos, quais valores que eles consideram mais e menos importantes para seus filhos, bem como analisar qualitativamente suas justificativas.

Os seis valores que mais se repetiram nas três modalidades de questionamento (Escala, Escolha Abrangente e Escolha Específica) foram: honesto, responsável e determinado (mais importantes), assim como ambicioso, líder e seguir regras dos pais (menos importantes). Considera-se, assim, que houve uma tendência avaliativa coerente nas três modalidades, reforçando a preponderância desses valores em detrimento dos demais para a amostra investigada.

A honestidade foi considerada o valor mais importante, ou seja, aquele mais desejado pelos participantes. Como os valores na criação dos filhos são 
influenciados pelo pertencimento dos pais a certo grupo cultural (Martins et al., 2015), parece haver um cuidado destes em não incentivar, em seus filhos, algumas práticas desonestas comuns à sociedade brasileira. Uma delas parece ser o "jeitinho brasileiro", o qual "faz do 'pode-se dar um jeito' uma forma de sobrevivência cultural, um costume que passa de geração em geração e busca eliminar as barreiras que impedem o alcance da meta [...] e pode servir de pretexto [...] a práticas fraudulentas" (Veludo-de-Oliveira, Aguiar, Queiroz, \& Barrichello, 2014, pp. 77-78). A importância da honestidade, então, parece justificar-se pela carência deste valor na sociedade brasileira contemporânea.

Em cada um dos três valores mais importantes, apareceram dois tipos de justificativas: (a) uma que considerou o valor como um meio; e (b) outra que o entendeu como um fim em si mesmo. No primeiro caso, o valor foi entendido apenas como algo necessário para se conseguir certos objetivos, como, por exemplo, arranjar um emprego, ganhar dinheiro, etc. Constitui-se, então, como um valor instrumental e não como um valor em si. No segundo, o valor foi considerado como bom em si mesmo, dando sentido à vida dos participantes (Prestes et al., 2014). Isso significa que, mesmo que se tenha escolhido ser honesto, determinado e responsável como valores mais importantes, a concepção sobre eles apareceu de forma distinta. Este resultado ressalta a relevância de análises qualitativas na investigação sobre valores, pois um estudo quantitativo não seria suficiente para acessar essa diferença.

Embora não estivesse elencado de forma explícita nas perguntas do instrumento, um dos aspectos que transpassou as respostas sobre os três valores mais importantes foi a preocupação com a preparação dos filhos para o futuro. No geral, os pais quiseram o sucesso dos filhos (Kohn, 1995; Tudge et al., no prelo) e perceberam que as crianças necessitavam estabelecer metas a longo prazo (Jaramillo, Pérez, \& González, 2013). Para Monteiro e Santos (2011), as metas, de certa forma, representam valores e práticas estabelecidas ao longo da vida do indivíduo - principalmente dos jovens - e farão parte de seus comportamentos futuros. Assim, enquanto ser honesto apareceu como um meio para atingir um objetivo futuro, ser determinado representou uma espécie de força propulsora para alcançá-lo. Já ser responsável foi apontado como uma característica a ser incentivada desde a infância para abarcar as responsabilidades de quando os filhos crescerem. Por serem valores relevantes, estudos anteriores (e.g., Macedo et al., 2006) já haviam apontado a honestidade e a responsabilidade como características que deveriam ser transmitidas pelos próprios pais.

A ambição foi entendida como o valor menos importante pelos pais. Dentre todos os valores da escala, este é aquele mais relacionado ao dinheiro e ao poder, valores estes que, em um estudo anterior no Brasil (Sarriera et al., 2012), também foram considerados pelos pais como de menor relevância na vida dos filhos. Para Sarriera e colegas, a menor importância desses valores parece 
estar ligada aos projetos de vida que os pais fazem para seus filhos. Os autores afirmaram que, como está cada vez mais comum que haja dependência financeira até os 21 anos, os pais têm considerado que é mais relevante que os filhos pensem em uma formação continuada do que focarem sua atenção em projetos ambiciosos desde cedo.

Seguir as regras dos pais, por sua vez, surgiu como um dos valores menos importantes por ser considerado significativo apenas na infância e por dar lugar à construção das próprias regras com o passar dos anos. Assim, de forma geral, houve uma valorização da autonomia e da autodireção. Apesar de não ser o mais comum (Piaget, 1936/2014a, 1954/2014b), isso está de acordo com a amostra investigada, uma vez que ela é proveniente de um grande centro urbano e a maioria dos participantes havia frequentado, no mínimo, alguns anos em uma instituição de Ensino Superior. Conforme Kohn (1995), os valores de pais na criação dos filhos, na maioria das sociedades industrializadas, estão relacionados a experiências anteriores de educação e trabalho. Normalmente, os pais com maior nível educacional também possuem um trabalho que os permite pensar por si próprios, o que os leva a acreditar que, para se alcançar o sucesso, é necessário ter autonomia e autodireção. Como os pais usualmente desejam sucesso para seus filhos, eles priorizam esses valores na criação das crianças, evitando estimular a conformidade e a obediência (Tudge et al., no prelo).

Como honestidade e ambição obtiveram, respectivamente, a maior e a menor média na Escala e a maior e a menor importância nas Escolhas Específicas 1 e 2, o tema da alteridade e da empatia adquiriram lugar de destaque. Sobre ser honesto, diversas falas indicaram que esta seria uma forma de não fazer mal às outras pessoas. Contemplou-se a relevância de "não passar a perna", "não trapacear" e "não prejudicar". Em relação a ser ambicioso, diversos participantes mencionaram que assim seria possível prejudicar, não apenas a própria pessoa, mas também aquelas ao seu redor. Destarte, o indivíduo ambicioso foi considerado capaz de fazer mal para qualquer pessoa para conseguir o que quer. Para Formiga e Souza (2012), a empatia estaria associada positivamente a uma orientação cultural coletivista, e negativamente a uma orientação individualista.

Mantendo-se essa ideia de orientação coletivista, percebe-se claramente a valorização dos pais em relação às relações interindividuais, ou seja, o relacionamento dos filhos com outras pessoas. A atribuição de valor a aspectos interpessoais pode estar relacionada às experiências e vivências dos pais características do mundo adulto (Sarriera et al., 2012), as quais estão permeadas por afetos interindividuais e pela cooperação entre pares (Piaget, 1932/1994, 1954/2014b). Houve, então, uma valorização, ao mesmo tempo, da independência e da relação, o que seria o esperado para a amostra, uma vez que este tipo de valorização é característico das zonas urbanas de países em desenvolvimento (Kağitçibaşi, 2012). 
Os resultados da pesquisa vão ao encontro do trabalho de Tam et al. (2012), o qual estabeleceu que os pais não somente desejam transmitir a seus filhos os valores que eles próprios valorizam, mas também os que percebem enquanto normativamente importantes para a sociedade. Entretanto, é possível que os participantes tenham enfatizado respostas consideradas socialmente desejáveis, minimizando aspectos culturalmente reprováveis. Essa tendência em transmitir uma imagem aceitável e de acordo com as normas sociais é denominada desejabilidade social (Beretvas, Meyers, \& Leite, 2002), a qual pode interferir em opiniões, atitudes e valores (Schmitt \& Steyer, 1993). Essa é uma limitação do presente estudo, uma vez que pode ter havido vieses nas respostas dos pais ao relatarem o que consideram mais e menos importantes para seus filhos.

Como esperado, tendo em vista o método selecionado, evidenciou-se que, por todos os valores serem em certo sentido desejáveis, as médias não foram suficientes para detectar de forma adequada as diferenças entre eles. O uso de uma metodologia mista - com auxílio das entrevistas e escolhas dentre vários valores - foi uma alternativa interessante para ir além dos resultados a partir das médias. A profundidade da metodologia qualitativa, aliada ao cruzamento com dados quantitativos, é particularmente útil para o estudo de fenômenos muito complexos (Ritchie \& Lewis, 2003), dando uma maior confiabilidade acerca da escolha dos valores almejados pelos pais a seus filhos.

Cabe notar, entretanto, que os instrumentos utilizados, por tratarem de valores apreciáveis, proporcionaram justificativas mais ricas e detalhadas aos valores mais importantes (Escolhas 1) quando comparadas com as dos menos relevantes (Escolhas 2). Grande parte dessas justificativas situaram os valores de menor importância em uma comparação aos valores de maior importância, e não propriamente através de características do valor em si. Além disso, ao se pedir ao participante uma justificativa de sua escolha, pode-se ter incitado respostas no sentido do valor não ser importante por si só, mas apenas como um meio para se atingir determinado objetivo.

\section{CONSIDERAÇÕES FINAIS}

A investigação dos valores de pais em relação a seus filhos remete a uma transmissão de valores entre gerações, a qual influi tanto no desenvolvimento individual quanto no funcionamento da sociedade (Barni et al., 2013). A construção dos valores só é possível por meio de um processo, o qual se realiza em estreita ligação com o ambiente (Piaget, 1954/2014). Acredita-se, assim, que o estudo dos valores almejados para os filhos, além de permitir identificar seus níveis de importância (bem como as justificativas para estes níveis), possibilitam entender melhor o momento sociocultural atual. Assim, entende-se, como La Taille e Menin (2009), que não se pode falar apenas em uma falta ou inversão de 
valores, mas que se deve considerar também que os valores estão em transformação.

Acerca da presente investigação, considera-se que outras variáveis não controladas nesta pesquisa possam ter influência nos resultados, como a modalidade de cuidador (pais, mães e avós), a classe social, o emprego e a escolaridade dos pais. Futuras pesquisas poderiam abordar diferenças na atribuição dos valores nos diferentes grupos sociodemográficos, principalmente no que se refere à classe social, ao emprego e à escolaridade dos pais (Kohn, 1995; Kohn et al., 1986; Kohn et al., 2001; Martins et al., 2015; Tudge, et al., 2000; Tudge et al., 2013; Vieira et al., 2010). Como a compreensão dos diferentes participantes acerca dos significados dos valores parece não ter sido a mesma, outros estudos também poderiam se debruçar sobre estes significados. Assim sendo, pensa-se que o tema dos valores, por envolver questões importantes para áreas como a Psicologia, a Educação, a Filosofia e a Sociologia (Menin, Bataglia, \& Zechi, 2013), consiste em um assunto interdisciplinar, o qual deve ser investigado de forma integrada pelos mais diferentes ramos do conhecimento.

Cabe destacar a importância da reflexão sobre quais são os tipos de valores que se deseja desenvolver na sociedade. Além disso, cabe perguntar quais são as concepções que estão por trás dos valores a serem desenvolvidos, uma vez que, como visto, um mesmo valor pode ser encarado ora como algo instrumental ora como um fim em si mesmo. Por fim, acredita-se que o estudo dos valores almejados para os filhos possibilita elaborar programas e políticas públicas dirigidas tanto aos pais quanto aos jovens (Sarriera et al., 2012). Permite-se, dessa forma, não apenas promover a assimilação de valores externos, mas também criar espaços para o desenvolvimento da moralidade dos indivíduos, através da construção autônoma dos próprios valores em uma relação de cooperação (Piaget, 1932/1994).

\section{REFERÊNCIAS}

Barbosa, L. (2006). O jeitinho brasileiro: a arte de ser mais igual do que os outros. Rio de Janeiro: Elsevier.

Bardin, L. (2010). Análise de conteúdo. Lisboa: Edições 70. (Trabalho original publicado em 1977).

Beretvas, S. N., Meyer, J. L., \& Leite, W. L. (2002). A realibility generalization study of the Marlowe-Crowne Social Desirability Scale. Educational and Psychological Measurement, 62(4), 570-589.

Barni, D., Alfieri, S., Marta, E., \& Rosnati, R. (2013). Overall and unique similarities between parents' values and adolescent or emerging adult children's values. Journal of Adolescence, 36, 1135-1141. doi: 10.1016/j.adolescence.2013.09.002 
Dellazzana, L. L., \& Freitas, L. B. L. (2012). Cuidado entre irmãos: A parentalidade além da mãe e do pai. In C. A. Piccinini, \& P. Alvarenga (Eds.). Maternidade e paternidade: a parentalidade em diferentes contextos (pp. 319-340). São Paulo: Casa do Psicólogo.

Formiga, N., \& Souza, M. A. (2012). Tipo de orientação cultural e empatia em brasileiros: Verificação de um modelo teórico. Estudos Interdisciplinares em Psicologia, 3(2), 139-161.

Jaramillo, J. M., Pérez, L., \& González, K. A. (2013). Metas de socialización maternas: Relación con edad, formación académica y zona habitacional. Revista Latinoamericana de Ciencias Sociales, Niñez y Juventud, 11(2), 719-739.

Kağitçibaşi, C. (2012). Sociocultural change and integrative syntheses in human development: Autonomous-related self and social-cognitive competence. Child Development Perspectives, 6, 5-11. doi:10.1111/j.17508606.2011.00173.x

Keller, H. (2012). Autonomy and relatedness revisited: Cultural manifestations of universal human needs. Child Development Perspectives, 6(1), 12-18.

Kohn, M. L. (1995). Social structure and personality through time and space. In P. Moen, G. H. Elder, Jr., \& K. Lüscher (Eds.), Examining lives in context: Perspectives on the ecology of human development (pp. 141-168). Washington, DC: American Psychological Association.

Kohn, M. L., Slomczynski, K. M., \& Schoenbach, C. (1986). Social stratification and the transmission of values in the family: a cross-national assessment. Sociological Forum, 1, 73-102.

Kohn, M. L., Zaborowski, W., Janicka, K., Mach, B. W., Khmelko, V., Slomczynski, K. M., Heyman, C., \& Podobnik, B. (2001). Complexity of activities and personality under conditions of radical social change: a comparative analysis of Poland and Ukraine. Social Psychology Quarterly, 63(3), 187-208.

La Taille, Y., \& Menin, M. S. (2009). Crise de valores ou valores em crise?. Porto Alegre: Artmed.

Macedo, R. M. S., Kublikowski, I., \&. Berthoud, C. M. E. (2006). Valores positivos e desenvolvimento do adolescente: Uma perspectiva dos pais. Revista Brasileira de Crescimento Desenvolvimento Humano, 16(2), 38-52.

Martins, G., Gonçalves, T., Marin, A., Piccinini, C. A., Sperb, T. M., \& Tudge, J. (2015). Social class, workplace experience, and child-rearing values of mothers and fathers in southern Brazil. Journal of Cross-Cultural Psychology, 46(8), 996-1009.

Menin, M. S., Bataglia, P. U., \& Zechi, J. A. (2013). Projetos bem-sucedidos de educação em valores: Relatos de escolas públicas brasileiras. São Paulo: Cortez. 
Minayo, M. C. (2010). O desafio do conhecimento: Pesquisa qualitativa em saúde. São Paulo: Hucitec.

Monteiro, R. M., \& Santos, A. A. (2011). Motivação para aprender: Diferenças de metas de realização entre alunos do ensino fundamental. Estudos Interdisciplinares em Psicologia, 2(1), 19-35.

Piaget, J. (1994). O juízo moral na criança. São Paulo: Summus. (Trabalho original publicado em 1932)

Piaget, J. (2014a). O nascimento da inteligência na criança. Rio de Janeiro: LTC. (Trabalho original publicado em 1936).

Piaget, J. (2014). Relações entre a afetividade e a inteligência no desenvolvimento mental da criança. Rio de Janeiro: WAK Editora. (Trabalho original publicado em 1954).

Pinto, K. L. B., Arrais, A. da R., \& Brasil, K. C. T. R. (2014). Avosidade x maternidade: a avó como suporte parental na adolescência. Psico-USF, 19(1), 37-47. doi:10.1590/S1413-82712014000100005

Prestes, A. C., Castro, F. M., Tudge, J. R. H., \& Freitas, L. B. L. F. (2014). Desenvolvimento de valores em crianças e adolescentes. Leopoldianum, 40(110-2), 25-36.

Ritchie, J., \& Lewis, J. (2003). Qualitative research practice: a guide for social science students and researchers. London: Sage.

Sarriera, J. C., Ximenes, V. M., Bedin, L., Rodrigues, A. L., Schütz, F. F., ..., \& Silva, C. L. (2012). Bem-estar pessoal de pais e filhos e seus valores aspirados. Aletheia, 37, 91-104.

Schmitt, M. J., \& Steyer, R. (1993). A latent state-trait model (not only) for social desirability. Personality and Individual Differences, 14(4), 519-529.

Schwartz, S. H. (2012). An Overview of the Schwartz Theory of Basic Values. Online Readings in Psychology and Culture, 2(1), 1-20. doi:10.9707/23070919.1116

Sousa, V. de, Amaral, D. H., \& Dias, C. M. de S. B. (2014). Recasamento: Percepções e vivências dos filhos do primeiro casamento. Estudos de Psicologia (Campinas), 31(2), 191-201. doi:10.1590/0103$166 \times 2014000200005$

Tam, K. P., Lee, S. L., Kim, Y. H., Li, Y., \& Chao, M. M. (2012). Intersubjective Model of Value Transmission: Parents Using Perceived Norms as Reference When Socializing Children. Personality and Social Psychology Bulletin, 38(8), 1041-1052. doi:10.1177/0146167212443896

Tudge, J. (2008). The everyday lives of youg children: Culture, class, and child rearing in diverse societies. New York: Cambridge University Press.

Tudge, J., Hogan, D., Snezhkova, I., Kulakova, N., \& Etz, K. (2000). Parents' child-rearing values and beliefs in the United States and Russia: The impact of culture and social class. Infant and Child Development, 9, 105-121. 
Tudge, J., Lopes, R. S. C., Piccinini, C. A., Sperb, T. M., Chipenda-Dansokho, S., Marin, A. H., . . . Freitas, L. B. L. (2013). Child-rearing values in southern Brazil: Mutual influences of social class and parents' perceptions of their children's development. Journal of Family Issues, 34, 1379-1400. doi: $10.1177 / 0192513 \times 12453820$

Tudge, J., Martins, G., Vargas, E., Dellazzana-Zanon, L., Piccinini, C., \& Freitas, L. (no prelo). Children, families, and communities in Brazil: a culturalecological approach to child-rearing values and practices. In M. Fleer \& B. von Oers (Eds.), International handbook on early childhood education. New York: Springer.

Veludo-de-Oliveira, T., Aguiar, F., Queiroz, J., \& Barrichello, A. (2014). Cola, plágio e outras práticas acadêmicas desonestas: um estudo quantitativodescritivo sobre o comportamento de alunos de graduação e pós-graduação da área de negócios. Revista de Administração Mackenzie, 15(1), 73-97

Vieira, M. L., Seidl-de-Moura, M. L., Mafioletti, S. M., Martins, G. D. F., Tokumaru, R. S., Lordelo, E., ..., \& Keller, H. (2010). Autonomy and interdependency: Beliefs of Brazilian mothers from state capitals and small towns. The Spanish Journal of Psychology, 13, 816-824. doi: $10.1017 /$ S113874160000247X

\section{Sobre os autores}

Felipe Queiroz Siqueira é psicólogo pela Universidade Federal do Ceará (UFC) e mestre em Psicologia pela Universidade Federal do Rio Grande do Sul (UFRGS). É doutorando do Programa de Pós-Graduação em Psicologia da UFRGS, membro do Laboratório de Psicologia e Epistemologia Genética (LAPEGE) e trabalha na linha de Desenvolvimento Humano. Recebe financiamento de pesquisa da CAPES. E-mail: felipeqsiqueira@gmail.com

Tiago Zanatta Calza é psicólogo pela Universidade Federal do Rio Grande do Sul (UFRGS) e mestre em Psicologia pela mesma instituição. Atualmente faz doutorado pelo Programa de Pós-Graduação em Psicologia (UFRGS), onde trabalha na linha de pesquisa relativa ao Desenvolvimento Humano e à Personalidade. Recebe financiamento de pesquisa da CAPES. E-mail: tiagozcalza@gmail.com

Jorge Castellá Sarriera é psicólogo (título homologado no Brasil pela Universidade Católica de Pelotas), mestre em Psicologia Escolar pela Pontifícia Universidade Católica do Rio Grande do Sul, doutor em Psicologia Social pela Universidade Autônoma de Madrid e pós-doutor pela Universidade de Barcelona e pela University of San Francisco. Atua nas linhas de Desenvolvimento Humano e Psicologia Social Comunitária. Recebe financiamentos de pesquisa da CAPES e do CNPq. E-mail: jorgesarriera@gmail.com

Lia Beatriz de Lucca Freitas é doutora em Psicologia pela Universidade de São Paulo (USP), professora do Programa de Pós-Graduação em Psicologia da 
Universidade Federal do Rio Grande do Sul (UFRGS), onde coordena o LAPEGE Laboratório de Psicologia e Epistemologia Genética, bolsista de produtividade do CNPq e membro do grupo de pesquisa More than Thank You. E-mail: Iblf@ufrgs.br

\section{Agradecimentos}

Ao pesquisador Jonathan Richard Henry Tudge, pelo auxílio com os instrumentos e a análise, às colegas Andressa Carvalho Prestes e Fernanda Maria Palhares de Castro, pela ajuda na coleta de dados, e aos participantes da pesquisa. A quarta autora agradece ao apoio financeiro do CNPq (Processo $n^{\circ} 301714 / 2012-6$ ).

Recebido em: 14/04/2016

Revisado em: 27/09/2016

Aceito em: 02/10/2016 